\title{
Energy performance investigation of a district cooling system
}

\author{
A. Bukshaisha \& A. H. Beitelmal \\ Qatar Environment and Energy Research Institute, \\ Qatar Foundation, Qatar
}

\begin{abstract}
A steady-state model is developed to investigate the effect of the chilled water supply temperature and the inlet condenser water temperature on the performance of the centralized chiller system. The current results show that increasing the chilled water supply temperature by $1{ }^{\circ} \mathrm{C}$ increases the coefficient of performance (COP) of the chiller by $1 \%$ to $3 \%$ and reduces the total cooling system power consumption by an average of $2 \%$ when operating the chiller system at the design capacity level. Decreasing the entering condenser water temperature by $1^{\circ} \mathrm{C}$ increases the chiller COP by an average of $2 \%$ and reduces the total power demand by an average of $1.5 \%$. The reduction in the power consumption translates into a measurable annual reduction in $\mathrm{CO}_{2}$ emissions. The amount of $\mathrm{CO}_{2}$ emissions reduction depends on the type of fuel used to produce the electricity available for the chiller system. The current results also show that the chilled water temperature can be safely raised to a higher set point temperature than the industry standard set point of $5-6^{\circ} \mathrm{C}$ while preserving the cooling capacity requirements. In addition, the current results suggest that chilled water supply temperature set point of $8^{\circ} \mathrm{C}$ to $10^{\circ} \mathrm{C}\left(46^{\circ} \mathrm{F}\right.$ to $\left.50^{\circ} \mathrm{F}\right)$ would provide energy savings of $5 \%$ and $9.8 \%$, respectively, over the base case used of $6^{\circ} \mathrm{C}$ while reducing the carbon footprint by the same percentage.
\end{abstract}

Keywords: district cooling, centralized chiller system, HVAC, energy efficiency.

\section{Introduction}

Air-conditioning (AC) systems become vital and necessity to the day-to-day working and living conditions in hot climate countries such as the Gulf States where summer weather lasts longer than a few months and the maximum 
temperature of the summer season may exceed $50^{\circ} \mathrm{C}\left(122^{\circ} \mathrm{F}\right)$. The challenges that $\mathrm{AC}$ designers and building owners face such as capital and operating costs, reliability, flexibility and environmental sustainability to keep their occupants comfortable and at the right temperature are great.

District cooling provides an effective solution to such challenges while meeting the comfort level expected by the building occupants. Centrifugal chillers are typically selected for district cooling systems when the required cooling capacity is more than 400 tons. District cooling is a booming business in the Gulf countries where chilled water is produced and delivered through insulated underground pipe networks to various buildings throughout the district that is being served. Air handler units (AHU) condition the local air inside the building through the exchange of heat with the supplied chilled water. The capacity supplied to each building is usually based on the maximum calculated design cooling capacity which is typically overprovisioned and sometimes exaggerated based on the maximum ambient temperature ever recorded locally. The chilled water is typically supplied at a constant temperature of $4-5^{\circ} \mathrm{C}$. The chilled water supplied will increase by $1-2^{\circ} \mathrm{C}$ as it travels through the pipeline network and by the time it reaches each of the AHUs inside the targeted buildings. At $6-7^{\circ} \mathrm{C}$ the chilled water is still fairly low for the exchange of heat requirements by the AHU to lower the temperature of the air inside the building to a comfortable level of $20-22^{\circ} \mathrm{C}$. Although such requirements depend on the effectiveness of the heat exchanger inside the AHU however the current state of the art heat exchangers typically are designed for a temperature differential of $10^{\circ} \mathrm{C}$. District cooling systems have being incorporated in many countries in recent years as a method of conserving energy; yet high power usage is still due to air-cooling. Thus increasing the efficiency of the centralized chiller systems will produce the highest return in terms of energy savings and reduction in the carbon footprint associated with that savings.

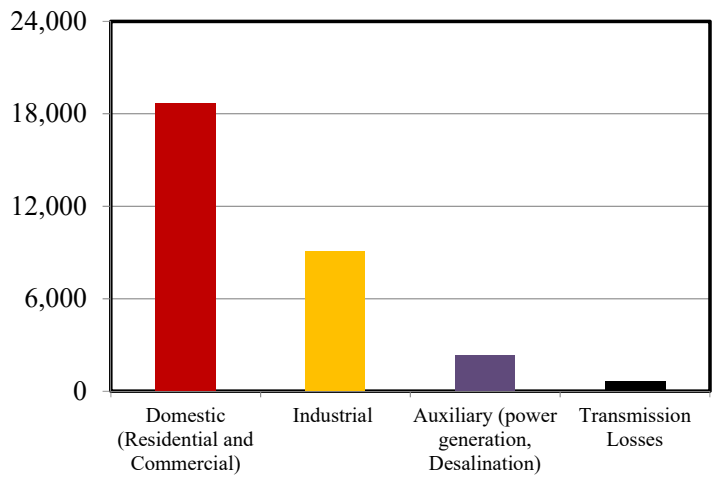

Figure 1: Typical energy consumption distribution by sector for Qatar [1].

Many of the Gulf countries are now considering that energy efficiency is an important building block for a sustainable development as it strengthens their national energy security and minimizes the negative impact on the environment. 
Implementing energy efficiency measures at both the demand and supply sides will lead to a significant reduction in energy consumption and reduces the stress on the utility power plants. Figure 1 displays the energy consumption distribution in 2011 for the State of Qatar where the lion's share of the energy consumed of more than $60 \%$ is used by commercial and residential buildings [1]. Air-cooling systems are the highest energy consumer in buildings.

Figure 2 displays Qatar monthly energy generation for 2011 [1]. Notice that energy consumption during the summer months roughly extend from May to October of each year exhibited an average increase in power consumption by about $30 \%$ on the average over the rest of the year which can be attributed to the increase demand on the air conditioning resources.

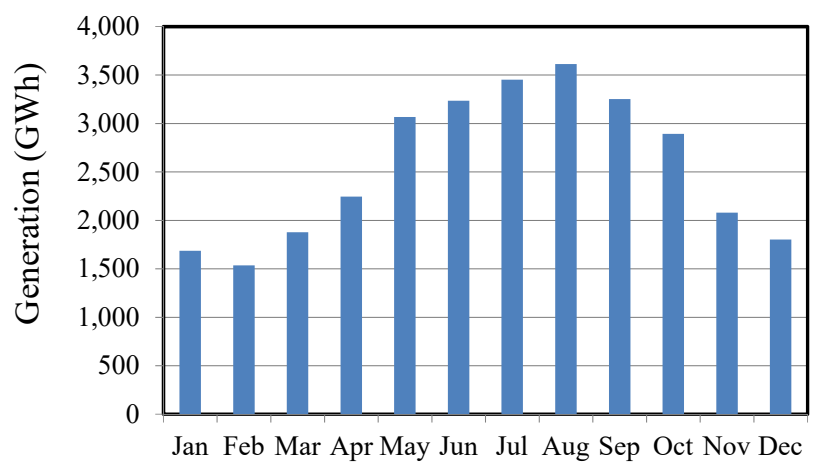

Figure 2: Monthly electric energy generation for the State of Qatar in [1].

District cooling systems companies are a major provider of chilled water to buildings and reducing the energy consumed by these providers will have a positive impact on the environment while reducing the demand for the electric power. In this paper, a steady-state model for a centralized chiller system is used to investigate the effect of the ambient conditions such and the chilled water supply set point temperature on the energy performance of the chiller system. The current model is built using the Engineer Equation Solver (EES) commercial software [2]. The EES software is capable of solving multiple sets of differential and non-linear equations with built-in functions, transport properties and thermodynamic functions [3]. Previous work [4, 5] showed that such assessment with such approach can prove useful in predicting limits and flexibilities.

\section{Model description}

Figure 3 displays a schematic of the computer model used for this study. The chiller power consumption which is mainly the power consumed by the compressor is a function of the temperature and the heat load on the chiller. 


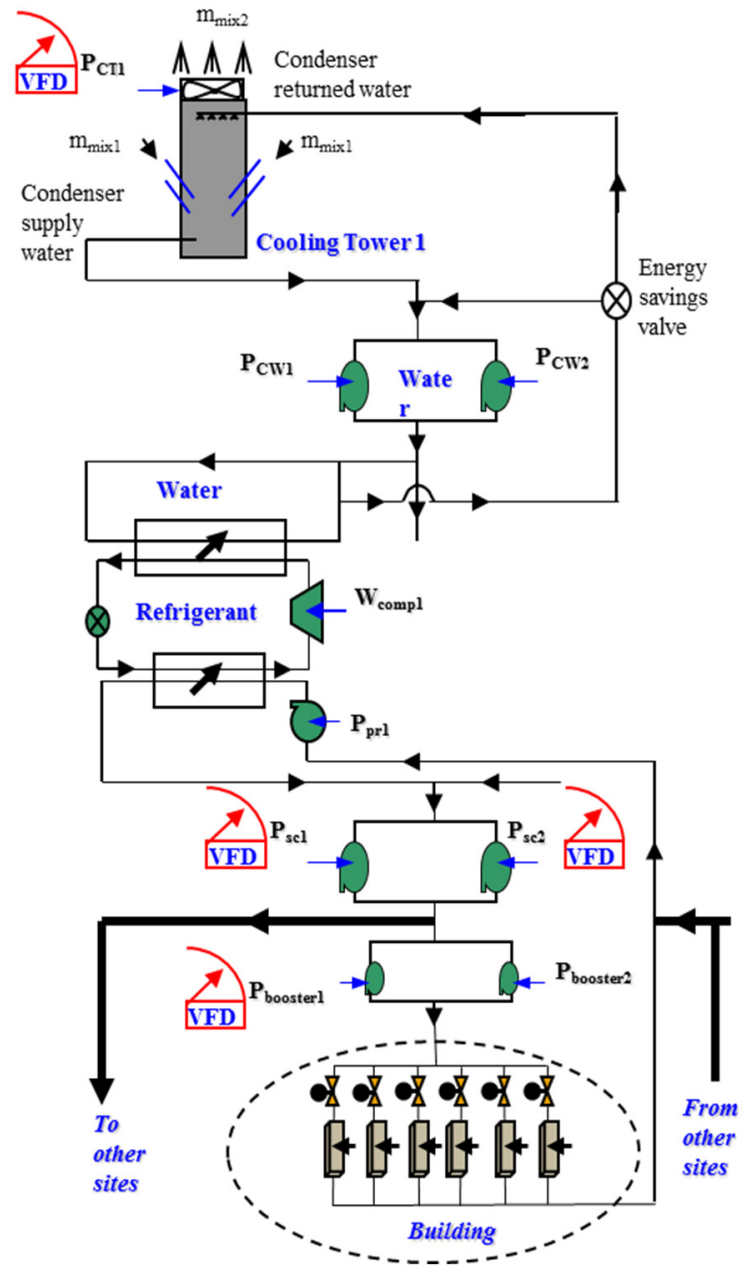

Figure 3: A schematic of a typical centralized chiller system.

The chiller power consumption can be presented in a dimensionless format (CPR) as shown in eqn (1) and it is defined as the ratio between the compressor power $\left(\mathrm{W}_{\text {comp }}\right)$ and the compressor power design value $\left(\mathrm{W}_{\text {comp-design }}\right)[6]$ :

$$
\mathrm{CPR}=\frac{\mathrm{w}_{\text {comp }}}{\mathrm{W}_{\text {comp-design }}}
$$

CPR can be calculated experimentally using eqn (2).

$$
\text { CPR }=a_{0}+a_{1} x+a_{2} x^{2}+a_{3} y+a_{4} y^{2}+a_{5} x y
$$


The coefficients $\left(a_{0}, a_{1}, a_{2}, a_{3}, a_{4}, a_{5}\right)$ are unique for each chiller type and can be determined using least-squares fit to an actual chiller performance data. The pressure drop seen by the condenser and the evaporator is already taken into account in eqn (2). The variable $\mathrm{x}$ can be determined separately using the ratio between the actual evaporator heat load $\left(\dot{\mathrm{Q}}_{\mathrm{evap}}\right)$ and the design evaporator heat $\operatorname{load}\left(\dot{\mathrm{Q}}_{\text {design }}\right)$ values:

$$
\mathrm{x}=\frac{\dot{\mathrm{Q}}_{\text {evap }}}{\dot{\mathrm{Q}}_{\text {evap-design }}}
$$

The variable $\mathrm{y}$ is defined as the ratio between the temperature differential of the condenser exist water temperature and the chilled water supply temperature $\left(\mathrm{T}_{\text {ctwr }}-\mathrm{T}_{\text {chws }}\right)$ to the design value for the same temperature differential $\left(\mathrm{T}_{\text {ctwr }}-\right.$ $\left.\mathrm{T}_{\text {chws }}\right)_{\text {design }}$ :

$$
\mathrm{y}=\frac{\left(\mathrm{T}_{\mathrm{ctwr}}-\mathrm{T}_{\mathrm{chws}}\right)}{\left(\mathrm{T}_{\mathrm{ctwr}}-\mathrm{T}_{\mathrm{chws}}\right)_{\text {design }}}
$$

The chiller coefficient of performance (COP) is the ratio between the evaporator load $\left(\dot{\mathrm{Q}}_{\mathrm{evap}}\right)$ and the actual compressor work $\left(\mathrm{W}_{\text {comp }}\right)$ :

$$
\mathrm{COP}=\frac{\dot{\mathrm{Q}}_{\text {evap }}}{\mathrm{W}_{\text {comp }}}
$$

where the actual compressor work is defined by:

$$
\mathrm{W}_{\text {comp }}=\frac{\mathrm{W}_{\text {comp }-\mathrm{s}}}{\eta_{\text {pol }} \eta_{\mathrm{m}}}
$$

$\left(\eta_{\text {pol }}\right)$ and $\left(\eta_{\mathrm{m}}\right)$ are the polytropic efficiency and the mechanical efficiency respectively.

The isentropic compressor work $\left(\mathrm{W}_{\text {comp-s }}\right)$ is calculated using the following equation:

$$
\mathrm{W}_{\text {comp-s }}=\left(\frac{\mathrm{k}}{\mathrm{k}-1}\right) \dot{\mathrm{m}}_{\mathrm{ref}} \mathrm{P}_{2} \mathrm{v}_{2}\left[\left(\frac{\mathrm{P}_{2}}{\mathrm{P}_{1}}\right)^{\left(\frac{\mathrm{k}}{\mathrm{k}-1}\right)}-1\right]
$$

$k=\frac{C_{p}}{C_{v}}$ where $C_{v}$ and $C_{p}$ are the specific heats for constant volume and constant pressure; respectively.

The energy balance on the cooling tower processes can be calculated by the following equations:

$$
\dot{\mathrm{Q}}_{\mathrm{ctair}}=\dot{\mathrm{m}}_{\text {ctair }}\left[\mathrm{C}_{\mathrm{p}-\mathrm{air}}\left(\mathrm{T}_{\mathrm{air} 2}-\mathrm{T}_{\mathrm{air} 1}\right)+\left(\omega_{2} \mathrm{~h}_{\mathrm{v} 2}-\omega_{1} \mathrm{~h}_{\mathrm{v} 1}\right)\right]
$$

The amount of water evaporated and lost to the air stream depends on the inlet air relative humidity and can be calculated by: 
162 Energy Production and Management in the 21st Century II

$$
\dot{\mathrm{m}}_{\text {Evaporated }}=\omega_{2}-\omega_{1}
$$

The makeup water required is determined by:

$$
\dot{\mathrm{m}}_{\mathrm{mkw}}=\frac{\dot{\mathrm{m}}_{\mathrm{ct}-\mathrm{air}} \dot{\mathrm{m}}_{\text {Evaporated }}}{\rho_{\mathrm{ctw}}}
$$

Other cooling tower industry terminologies such as the approach and the range are calculated by the following equations:

$$
\begin{gathered}
\text { Approach }=\left(\mathrm{T}_{\text {ctws }}-\mathrm{T}_{\mathrm{wb}}\right) \\
\text { Range }=\left(\mathrm{T}_{\mathrm{ctws}}-\mathrm{T}_{\mathrm{wb}}\right)=\frac{\dot{\mathrm{Q}}_{\mathrm{ct}}}{\left(\mathrm{Cp}_{\mathrm{ctw}} \dot{\mathrm{m}}_{\mathrm{ctw}}\right)}
\end{gathered}
$$

For the energy balance, the energy transfer to the air stream is approximately equal to the heat removed from the circulating condenser water flow:

$$
\dot{\mathrm{Q}}_{\text {cond }}=\mathrm{C}_{\mathrm{p}-\mathrm{ctw}} \dot{\mathrm{m}}_{\mathrm{ctw}}\left(\mathrm{T}_{\mathrm{ctwr}}-\mathrm{T}_{\mathrm{ctws}}\right)
$$

\section{Results and discussion}

In order to fully understand the effect of the different variables on the performance of the chiller system, each variable was tested in its own under control condition. The variables tested were ambient air temperature, relative humidity, and chilled water supply temperature. The following plots display the COP versus the percentage chiller load for the control experiment of each of the three variables.

Figure 4 shows the effect of ambient air temperature $\left(20^{\circ} \mathrm{C}-50^{\circ} \mathrm{C}\right)$ on the COP. For this case, the relative humidity was set to $60 \%$, while the chilled water supply temperature was set to $6^{\circ} \mathrm{C}$. The graph shows that lower ambient air temperatures result in a higher COP.

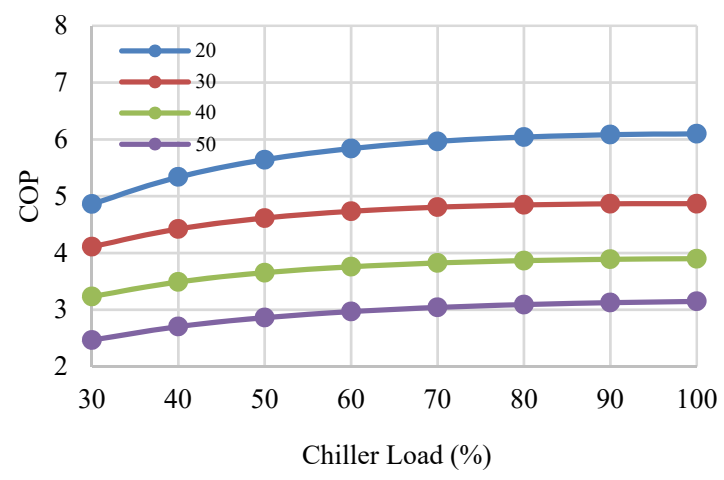

Figure 4: Effect of different air temperatures. 
Figure 5 displays the effect of relative humidity $(40 \%-70 \%)$ on the COP. Ambient air temperature was set to $30^{\circ} \mathrm{C}$, while the chilled water supply temperature was set to $6^{\circ} \mathrm{C}$. The graph shows that higher humidity rates result in lower COP values.

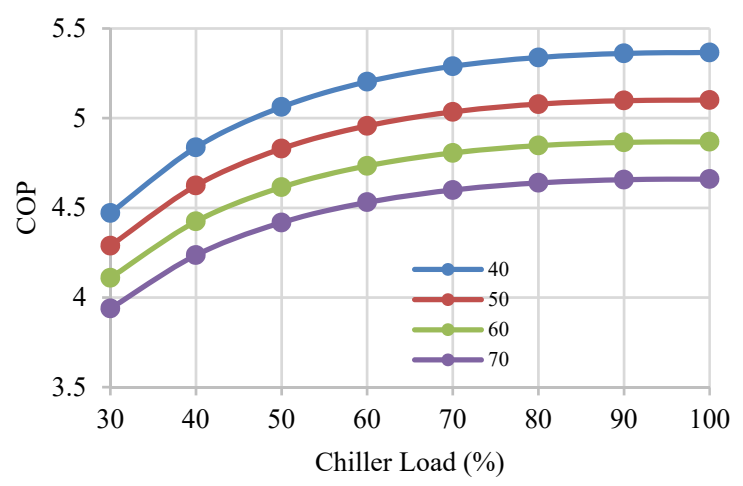

Figure 5: Effect of different humidity rates on COP.

In summary, a $10 \%$ decrease in relative humidity will increase the COP by an average of $4.4 \%$ and for every $1{ }^{\circ} \mathrm{C}$ change in the ambient air temperature will change the COP by an average of $1.6 \%$.

Figure 6 depicts the effect of the chilled water supply temperature on the COP. In this case, the ambient air temperature was set to $30^{\circ} \mathrm{C}$, while the relative humidity was set to $60 \%$. The chiller supply temperature is varied between $6^{\circ} \mathrm{C}$ and $14^{\circ} \mathrm{C}$. The graph indicates that higher chilled water supply temperature results in higher COP values. Unlike the previous two variables, the chilled water supply temperature is an independent variable and can be raised to a higher set point temperature.

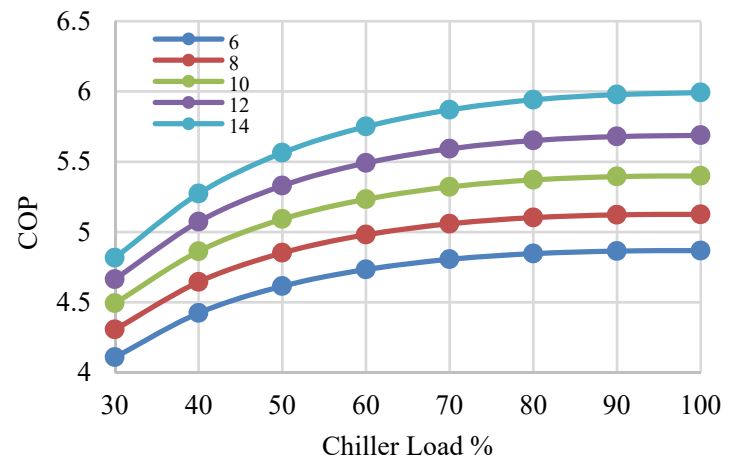

Figure 6: Effect of different chilled water supply temperature on COP. 
To further assess the effect of the chilled water supply temperature in terms of environmental impact the virtual experiments were conducted for the 12 months using the recorded average temperature and relative humidity for the State of Qatar. While conducting these experiments, the chiller is set to full capacity at $100 \%$. The results are used to calculate the corresponding amount of $\mathrm{CO}_{2}$ produced relative to the compressor power used by the chiller. Figure 7 displays the amount of the $\mathrm{CO}_{2}$ emitted at 3 selected chilled water supply temperatures of $6^{\circ} \mathrm{C}, 8^{\circ} \mathrm{C}$ and $10^{\circ} \mathrm{C}$ for each month of the year using the recorded average ambient temperature for each month.

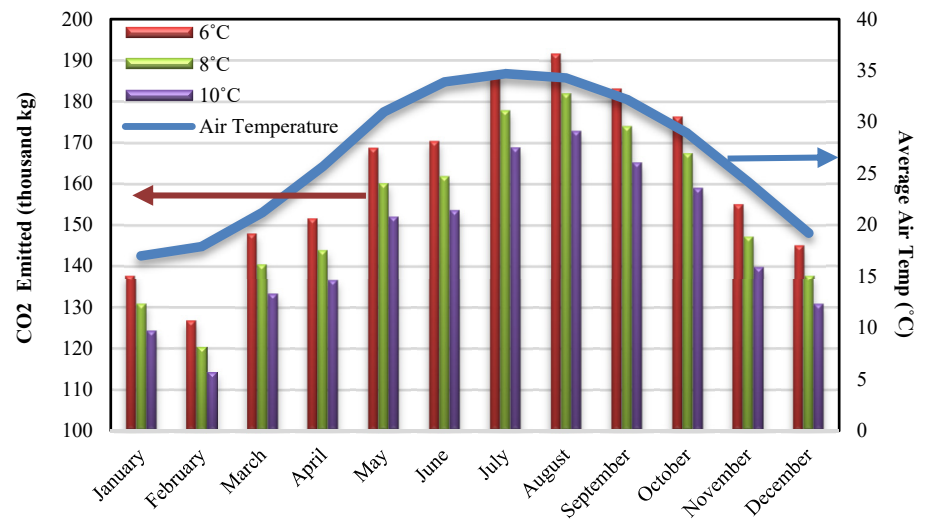

Figure 7: Effect of chilled water supply temperature on $\mathrm{CO}_{2}$ emissions.

Table 1 displays the estimated annual power consumption and the corresponding $\mathrm{CO}_{2}$ emissions for the 3 different chilled water supply temperature set points.

Table 1: Environmental impact between different chilled supply temperatures.

\begin{tabular}{|c|c|c|c|}
\hline $\mathrm{T}_{\text {chws }}\left({ }^{\circ} \mathrm{C}\right)$ & 6 (Base case) & 8 & 10 \\
\hline $\begin{array}{c}\text { Annual } \mathrm{CO}_{2} \text { emitted } \\
(\mathrm{kg})\end{array}$ & $1,941,527$ & $1,843,726$ & $1,750,693$ \\
\hline $\begin{array}{c}\text { Annual power } \\
\text { consumed }(\mathrm{kWh})\end{array}$ & $3,508,471$ & $3,331,738$ & $3,163,620$ \\
\hline $\begin{array}{c}\% \text { difference from } \\
\text { base case }\end{array}$ & - & $5.0 \%$ & $9.8 \%$ \\
\hline
\end{tabular}

The results show that increasing the chilled water supply temperature by $1^{\circ} \mathrm{C}$ will increase the COP by an average of $2.5 \%$. For example, raising the chilled water supply temperature from the base case of $6^{\circ} \mathrm{C}$ to $8^{\circ} \mathrm{C}$ and $10^{\circ} \mathrm{C}$ reduces the negative impact of the chiller system on the environment by $5 \%$ and $10 \%$, respectively. The lion's share of this improvement is observed in July and August; 
the hottest months of the year. It is important to note that the current experiments tested only up to $10^{\circ} \mathrm{C}$ for the chilled water supply temperature to account for possible heat gains during the delivery of the chilled water through the pipe network. The temperature of the air delivered to the end user is not affected by this change as the AHU will be able to condition the air delivered to the space.

\section{Summary and conclusion}

The results in this paper show that raising the chilled water supply temperature saves energy and reduces $\mathrm{CO}_{2}$ emission without compromising the quality of the service delivered to the end user. Hence this reduces operational costs and the negative impact on the environmental. Implementing this modification on the chilled water supply temperature set point does not require any additional costs. Applying such changes in an environment similar to Qatar's environment will result in the following outcomes:

- Increasing the chilled water supply temperature from $6^{\circ} \mathrm{C}$ to $8^{\circ} \mathrm{C}$ for 1 chiller saves an estimated $242 \mathrm{kWh}$ and that value translate to a reduction of $98,000 \mathrm{~kg}$ of $\mathrm{CO}_{2}$ annually.

- Increasing the chilled water supply temperature from $6^{\circ} \mathrm{C}$ to $10^{\circ} \mathrm{C}$ for 1 chiller saves an estimated $472 \mathrm{kWh}$ and that translate to a reduction of $191,000 \mathrm{~kg}$ of $\mathrm{CO}_{2}$ annually.

To illustrate, for the estimated 100 chillers within the city of Doha district, raising the chilled water supply temperature from $6^{\circ} \mathrm{C}$ to $10^{\circ} \mathrm{C}$ will reduce the annual energy consumption by an estimated $35 \mathrm{GW}$ and 19 million $\mathrm{kg}$ of $\mathrm{CO}_{2}$. This approximately a reduction of $10 \%$ from the base values at $6^{\circ} \mathrm{C}$.

\section{Nomenclature}

$\begin{array}{ll}C O P & \text { coefficient of performance; } \\ C p & \text { specific heat }(\mathrm{kJ} /(\mathrm{kg}-\mathrm{K}) ; \\ C P R & \text { compressor power ratio; } \\ \text { gpm } & \text { gallon per minute; } \\ h & \text { enthalpy }(\mathrm{kJ} / \mathrm{kg}) ; \\ m & \text { mass flow rate }(\mathrm{kg} / \mathrm{sec}) ; \\ P & \text { pressure }(\mathrm{kPa}) ; \\ Q & \text { heat transfer rate }(\text { Watts }) ; \\ T & \text { temperature }\left({ }^{\circ} \mathrm{C}\right) ; \\ v & \text { specific volume }(\mathrm{m} 3 / \mathrm{kg}) ; \\ W & \text { work }(\text { Watts }) ; \\ x & \text { evaporator heat load ratio; } \\ y & \text { temperature difference ratio; } \\ \omega & \text { specific humidity; } \\ \eta & \text { efficiency; } \\ \rho & \text { density }\left(\mathrm{kg} / \mathrm{m}^{3}\right) .\end{array}$




\section{Subscripts}

$\begin{array}{ll}\text { chws } & \text { chilled water supply; } \\ \text { comp } & \text { compressor; } \\ \text { ctw } & \text { cooling tower water flow; } \\ \text { ctwr } & \text { cooling tower water return; } \\ \text { ctws } & \text { cooling tower water supply; } \\ \text { evap } & \text { evaporator; } \\ m & \text { mechanical; } \\ m k w & \text { makeup water; } \\ \text { pol } & \text { polytropic; } \\ v & \text { vapor; } \\ w b & \text { wetbulb. }\end{array}$

\section{References}

[1] Qatar General Electricity \& Water Corporation "KAHRAMAA", Statistics Report 2011, 2011.

[2] Klein, S.A. \& Alvarado, F.L., Engineering Equation Solver. F-Chart software, Madison, Wisconsin, USA, 1992.

[3] National Institute of Standards and Technology, Thermodynamic Properties of Refrigerants and Refrigeration Mixtures Database (REFPROP). V.4.0, Gaithersburg, Maryland, USA, 1993.

[4] Beitelmal, A. H. \& Patel, C. D., A steady-state model for the design and optimization of a centralized cooling system, Int. J. Energy Research, Vol. 34: pp. 1239-1248, 2010.

[5] Beitelmal, A.H. \& Patel, C.D., Thermofluids Provisioning of a High Density High Performance Data Center, Technical Report No. HPL-2004-146R1, Hewlett Packard Laboratories, Palo Alto, California, USA, 2004.

[6] Braun, J.E. Methodologies for the design and control of central cooling plants. Ph.D. Thesis, University of Wisconsin, Madison, USA, 1988.

[7] Trane Company, Performance data tables for TRANE centrifugal chillers, 2006. 